\title{
La poesía de Antonio Ros de Olano
}

ALEJANDRO AMUSCO

Universidad de Barcelona

El día 7 de julio de 1886 salió de imprenta, si damos crédito al colofón del libro ${ }^{1}$, una cuidada recopilación de poemas de Antonio Ros de Olano ${ }^{2}$. Llevaba por título Poesías, y -al frente- un generoso pró-

1 Poesías, de Antonio Ros de Olano, Colección de escritores castellanos, Madrid, 1886. El colofón reza así: «Este libro se acabó de imprimirfen Madrid, en casa de / Manuel Tello, el dia / 7 de julio del / año de / 1886.» Se citará siempre por esta edición.

2 Don Antonio Ros de Olano, conde de Almina, marqués de Gual-el-Jelú, nació el 9 de noviembre de 1808 en Caracas, donde su padre, de origen catalán, militar que ejerció altos cargos en tierras venezolanas, se hallaba temporalmente destinado. Llegó con sus padres a España a la edad de cinco años; la familia se instala en la casa solariega de Puig-Alegre, en el Ampurdán (Gerona). Muy pronto huérfano, se ocupa de la educación del niño un tío suyo. Al igual que su padre, abrazó la carrera militar, comenzándola como Alférez de la Guardia Real. Sus servicios durante la primera guerra carlista (1833-1840), a las órdenes de los generales Mina y Fernández de Córdova, le llevan a ser nombrado pronto coronel (1837) y a entrar en la política activa como diputado independiente (1838). Protagonista importan- 
logo de Pedro A. de Alarcón, quien había combatido a las órdenes del general Ros en la guerra de Africa. A las pocas semanas de aparecer estas Poesías, fallece el laureado general y poeta, una de las figuras más controvertidas de su tiempo.

Más que de una recopilación completa, se trata de una muestra, una sucinta antología. De las incontables composiciones dispersas por las revistas de la época (Iris, El Pensamiento, Revista Contemporánea, Revista de España...) y por las obras en prosa del autor (El doctor Lañuela, Episodios militares...) fueron salvadas aproximadamente las dos terceras partes, e incorporadas al volumen tras un minucioso proceso de revisión; a veces, de reescritura. Al carácter selectivo de estas Poesías habría que añadir, pues, el de depuración.

No deja de ser extraño que ni prologuista ni autor hiciesen constar, aunque fuese en una simple nota, esta doble e importante condición. Máxime cuando, habiendo sido el juicio de los contemporáneos de Ros adverso o benévolamente condescendiente para con su poesía, ahora la muestra antológica venía a redimir de sus faltas a bastantes poemas. Tampoco se precisa en ningún sitio quién hizo la labor de selección, por lo que hay que suponer que debió de ser de la responsabilidad exclusiva del autor ${ }^{3}$.

te de la historia española, su nombre está vinculado a cuantos movimientos, revoluciones y contrarrevoluciones, se sucedieron en la agitada mitad de nuestro siglo XIX: propició la caída de Espartero (1843), participó con O'Donnell en la batalla de Vicálvaro (1854) y poco después en la acción contrarrevolucionaria que lleva de nuevo a Narváez al poder (1856). Su intervención decisiva al mando del tercer cuerpo de ejército en la guerra de Africa (1859-1860) le valió el marquesado de Guad-el-Jelú. Entre los innumerables cargos que desempeñó y títulos con que le honraron sus contemporáneos, destaca el haber sido caballero gran cruz de la Orden Real de Carlos III, de Isabel la Católica y de la militar de San Hermenegildo, ministro de Instrucción Pública y embajador de España en Portugal, presidente del Supremo de Guerra y Marina y senador vitalicio. Apoyó la Revolución de 1868. Murió en Madrid el 23 de julio de 1886.

3 No obstante, nos resistimos a creer que en ciertos poemas la corrección fuera hecha por el propio poeta. Entre los últimos poemas que publicó en Revista de España y la aparición de sus Poesías median pocos años; no se entiende cómo en ese corto espacio pudiera cambiar tan de raíz su concepción de bastantes poemas, que sufrieron grandes supresiones y algunos añadidos que los mejoran considerablemente. Los nuevos finales, sobre todo, ganan mucho. Los poemas quedan ahora bien cerrados, cosa que a Ros le costaba conseguir a juzgar por las primeras versiones. Sólo por la intervención de otra mano se comprendería también la existencia de ciertos lapsus o incorrecciones en la versión definitiva, como es el caso del soneto que dedica a Espronceda. Es un ejemplo que vale por muchos otros: cuatro años antes de aparecer Poesías, publica Ros un soneto en memoria de su amigo Espronceda en Revista de España, LXXXIV (28 enero, 1882), pp. 356-357. El verso once en la versión de la Revista era inadmisible. Ros conjuraba a Espronce- 
Angel María Segovia, severo censor de la época, indignado por la evolución acomodaticia del político que fue Ros de Olano, no manifiesta ninguna comprensión hacia su poesía: «Considerado Ros de Olano desde el punto de vista literario - dice-, lo mismo se podría hablar de él mucho que poco. Si este señor fuera exclusivamente literato, es decir, si no hubiera llegado en la política y en la carrera de las armas á la altura en que hoy le hemos colocado, no tendríamos para qué ocuparnos del hombre de letras, porque sería una de tantas vulgaridades como ruedan por el mundo confundidos con toda clase de gentes; pero como su posición en la milicia y en el mundo político ha puesto completamente de relieve su personalidad, de aquí el que se haya abultado también su mérito como hombre de letras.» Y continúa Segovia con su condena, en términos así de duros: «Ros de Olano ha tenido siempre, desde muy joven, una decidida afición a ser poeta; pero nunca ha llegado a serlo realmente; merece, sin embargo, el título de buen aficionado. / Nuestro personaje gusta mucho de la poesía alemana; sus melancolías le encantan, sus nieblas le seducen, sus misterios le atraen [...]; por esto, en muchas composiciones del Sr. Ros de Olano [...], se ve al poeta perdido en un laberinto de melancolías, de nieblas, de misterios y de supersticiones, del que no acierta a salir nunca, y en el que se complace andar errante siempre» ${ }^{4}$.

Al lado de esta valoración despreciativa, apoyada en consideraciones extraliterarias, otras más ecuánimes se dieron por escritores de autoridad, como Menéndez Pelayo o Valera, que hicieron justicia a los méritos de Ros. Incluso no faltó la reacción desmedidamente elogiosa, por la que Ros pasaba a ser un «eminentísimo poeta» ${ }^{5}$.

Para Valera, Ros merece, como poeta lírico, muy altas alabanzas. «Con leer sus versos — comenta-, toda persona de gusto se moverá a celebrarle, a simpatizar con él y hasta admirar su elegante originalidad y su sincero y hondo sentir y entender del mundo, de Dios y del hom-

da a salir de su tumba y a volver a la vida con este singular mandato: «Rompe la losa al golpe de tu frente.» La corrección cayó rápida sobre ese endecasílabo convirtiéndolo más suavemente en: «Rompe la losa con tu férrea mano.» Pero el juego de rimas, al sustituir mano a frente, quedó alterado, sin advertir el corrector que ese cambio comprometía a más versos (reelaboró dos finales, cuando debió hacerlo con tres). Así se explica que en la edición de Poesías el verso nueve de este soneto quede suelto ( «Poeta del pensar!... De la clemente»), pues rimaba en principio con frente.

4 Angel María Segovia, Figuras y figurones, II, Madrid, 1878, p. 719, $a$ y $b$.

5 Veáse José Navarrete, «Prólogo» a Episodios militares, de A. Ros de Olano, Madrid, 1884; especialmente pp. IX-XI. 
bre.» Y más adelante: «Sus versos casi siempre se recomiendan por la enérgica y sencilla claridad con que expresan los sentimientos y las ideas y la viva impresión que produce en el alma el Universo visible. Se diría - concluye Valera - que Ros, al menos al escribir sus mejores versos, tuvo presente y siguió esta sentencia que se le atribuye: "La poesía es pensar alto, sentir hondo y hablar claro"' ${ }^{6}$.

La disparidad de juicio que hubo en su día respecto a la obra de Ros, hoy se mantiene. Un siglo después de escrita, no hay acuerdo en su valoración; acaso, como arguye Salvador García, porque «su extravagancia e impenetrabilidad ha dado lugar a la impaciencia o a la desesperación de los críticos ${ }^{7}{ }^{7}$. Lo cierto es que, entre las antologías recientes de la poesía romántica española, encontramos los dos extremos: desde la que excluye a $\operatorname{Ros}^{8}$, hasta la que lo representa con un número de poemas sólo inferior a Bécquer y Espronceda, por delante incluso de Rosalía ${ }^{9}$.

Los poemas de Ros se presentan, en la edición de 1886, única hasta el presente, agrupados en seis secciones: 1) Sonetos (veintiún sonetos en total), 2) La Pajarera (que comprende diecisiete composiciones), 3) Doloridas (con once), 4) Por pelar la pava: tradición infernal (leyenda cómica en romance), 5) La Gallomagia (parodia épica en treinta octavas reales) y 6) Lenguaje de las Estaciones (introducción y cuatro extensos poemas dípticos). Se completa el volumen con una pieza teatral en verso, Galatea ${ }^{10}$, en cuyo comentario no entraremos por pertenecer a género literario distinto.

6 Juan Valera, «Notas biográficas y críticas», en Obras completas, II, Madrid, 1942, p. 1309. Da publicidad a la citada sentencia Manuel Ascensión Berzosa, quien la glosa en su prólogo a El doctor Lañuela, de A. Ros de Olano, con estas palabras: «Sentid hondo, pensad alto, hablad claro, según la fórmula feliz del que ha escrito este libro, y espiritualizaréis la materia, sensibilizaréis el espiritu, seréis poeta.» Lañuela, Madrid, 1863, pp. 8-9.

7 Salvador García, «El Pensamiento de 1841 y los amigos de Espronceda», Boletín de la Biblioteca Menéndez Pelayo, año XLIX, núms. 1, 2, 3 y 4 (enero-diciembre, 1968), p. 332.

8 Los poetas románticos, antología y prólogo de Antonio F. Molina, Barcelona, 1975.

9 Antologia de la poesía romántica española, selección e introducción de Joaquín Marco, Barcelona, 1972.

10 La advertencia que hace Ros de Olano al frente de su Galatea no puede ser más desorientadora, así como el subtítulo de «Fábula griega» con que la acompaña. Dice así esa advertencia: «Esta obra es refundición (con un acto más y más personajes) de la composición francesa del mismo título.» Con esta pista parece remitir a la conocida Galatée (1783) de Florián, cuyo éxito indujo a Casiano Pellicer, en 1797, a realizar su adaptación al castellano, y a Cándido María Trigueros a arreglar y continuar la versión anterior en Los enamorados o Galatea y sus bodas 
Además de esto, en prosa el general Ros de Olano publicó un tratado sobre la primera guerra carlista, Observaciones sobre el caracter militar y político de la guerra del Norte (1836); numerosas narraciones, entre las que sobresalen, por su extraño hechizo, La noche de máscara. Cuento fantástico (1841), Maese Cornelio Tácito. Origen del apellido de los Palominos de Pan-Corvo (1868), Historia verdadera o cuento estrambótico, que da lo mismo (1869), y el relato de fondo autobiográfico Jornadas de retorno escritas por un aparecido (1873). De 1840 es su primer intento de novela, El diablo las carga. De 1860, el opúsculo orientalista Leyendas de Africa, incluido más tarde, bajo el título de «Guad-el-Jelú (El río dulce). Tetuan (Tet-Tagüen)», en Episodios militares (1884), donde se registran, con una prosa cruda y expresiva, distintos momentos de la guerra de los Siete Años y de la mantenida con Marruecos ${ }^{11}$. Estas últimas páginas eran las predilectas de Menéndez Pelayo, las que mayor resistencia, creía él, opondrían al paso del tiempo ${ }^{12}$. Pero sin duda, si no lo mejor, lo más sugestivo de cuanto escribiera en prosa es la enigmática novela abierta El doctor Lañuela, que lleva por subtítulo Episodio sacado de las memorias de un tal Joséf, y que, a su aparición en Madrid el año 1863, atrajo el interés de los lectores más preparados ${ }^{13}$. Añádase a esta relación, para completar el espectro de la actividad literaria de Ros, la comedia en tres actos y en verso Ni el tío ni el sobrino, en colaboración con Espronceda, desafortunada imitación moratiniana cuyo estreno tuvo lugar en el teatro de la Cruz el 25 de abril de $1834^{14}$.

(1798). Durante el siglo XIX, se siguieron traduciendo y adaptando obras de Florián en España, de forma que su nombre era sobradamente conocido. De 1834 es la traducción de su novela pastoril en verso y prosa Estela, a cargo de V. Rodríguez Arellano; J. López de Peñalver tradujo su Gonzalo de Córdoba en 1854 . Pero, pese a todos los indicios, la Galatea de Ros de Olano no guarda relación alguna, ni remota, con Galatée, su cohorte de libres adaptaciones, ni tan siquiera con la leyenda clásica sobre la cual dice inspirarse.

11 Para la bibliografía de los textos narrativos del autor, véase Cuentos estrambóticos y otros relatos, de A. Ros de Olano, prólogo, selección y notas de Enric Cassany, Barcelona, 1980, pp. 37-38.

12 «En prosa quedará de él, más que sus novelas, las relaciones que escribió de algunos episodios de sus campañas, con más llaneza que de ordinario, en estilo vigoroso y realista, pero iluminado siempre por la rojiza llama de cierta fantasía tétrica y misantrópica que recuerda la de Goya en Los Desastres de la guerra.» M. Menéndez Pelayo, Historia de la poesía hispano-americana, I, Obras completas, XXVII, Santander, 1948, p. 396.

13 Mereció la atención crítica, entre otros, de Fernán Caballero, Castelar, Menéndez Pelayo y Cándido Nocedal. Véase prólogo de E. Cassany, op. cit., especialmente las pp. 16, 17 y 24.

14 Véase, acerca de este estreno, A. Cortón, Espronceda, Madrid, 1906, pp. 251-252. 


\section{Sonetos}

Comienza esta serie de sonetos con algunos muy del gusto del primer momento romántico. Los dos que encabezan la serie, «El conde don Julián» ${ }^{15} \mathrm{y}$ 《Los castillos de la Reconquista» ${ }^{16}$, se aproximan por su asunto al romanticismo descriptivo, de tendencia histórica y cristiana, cultivado por el Duque de Rivas.

«El conde don Julián» se basa en la leyenda de la traición de éste al conocer el ultraje de su hija Florinda a manos del rey don Rodrigo. En 1828, como es bien sabido, Rivas había terminado en su destierro de Malta el largo poema narrativo en octavas Florinda (comenzado en Londres), sobre idéntico episodio. Lo más probable es que Ros deOlano, atraído por la viveza y la fuerza del poema de Rivas - publicado en 1834 conjuntamente con El Moro expósito-, decidiera tratar, él también, el legendario tema. El resultado, de fácil retórica, no pasa de ser un ejercicio poético.

Igual tono mantiene «Los castillos de la Reconquista», si bien el sentimiento cristiano predomina ahora sobre el propiamente histórico. Los castillos son vistos como «esqueletos de gigante hechura» que dan testimonio aún del «tesón ibero» puesto en la Reconquista para hacer triunfar el cristianismo:

\section{Helos en pie; la Religión los vela: \\ [...] \\ Ilevan de Covadonga hasta Granada \\ la Cruz triunfante por blasón frontero.}

El tercer soneto, «Napoleón» ${ }^{17}$, es de factura similar a los dos precedentes. La colocaión antepuesta de los adjetivos y la fatuidad retórica delatan la proximidad temporal con que fueron escritos. Lo mismo cabe deducir del multiplicado uso que hacen del pretérito indefinido.

La figura de Napoleón, como la de César y otros grandes poderosos que dominaron las naciones y amenazaron la libertad, fue obsesión entre los poetas románticos, que habían hecho de la libertad misma el reducto sagrado del hombre. Sin salir de esta primera sección de la poesía de Ros, son frecuentes las alusiones a personajes poderosos. En el soneto IV de En la soledad se toma de nuevo como referente histórico la figura de un emperador: Carlos V. El tema es el apartamiento del mundo y de las tentaciones de la gloria. Carlos V se sitúa en su retiro de

\footnotetext{
15 A. Ros de Olano, Poesías, cit. en nota 1, p. 35.

16 Ibid., p. 36.

17 Ibíd., p. 37.
} 
Yuste: «Ni envidiar de los Césares la gloria» ${ }^{18}$. Y en el último soneto, «A un soldado», vuelven las alusiones a César y al Imperio de Roma (Catón, Bruto) ${ }^{19}$.

No ha faltado intérprete de la historia literaria que haya relacionado el levantamiento de los pueblos contra la invasión napoleónica con el Romanticismo naciente. «El Romanticismo — escribe Díaz Plaja ${ }^{20}$ surge de las reacciones militares que se oponen al cuño imperial unificador.» Ros de Olano no execra, sin embargo, en su soneto la actitud ofensiva napoleónica; intenta sólo definir la Historia tomando a Napoleón, dentro de ella, como hito delimitador:

No tuvo origen ni dejó herederos... vino al mundo a marcarle dos edades... iSu nombre pertenece al orbe entero!

Los cinco sonetos siguientes, agrupados bajo el título común de En la soledad, desarrollan el tópico de la calma y el sosiego del campo en contraposición al ajetreo de la ciudad. Tema horaciano, la influencia más directa en lo que hace al estilo la recibe de Fray Luis de León. $\mathrm{La}$ resonancia del clásico renacentista es notoria en los cinco sonetos (y aun en gran parte de su obra toda), pero especialmente en versos como los que a continuación extraemos:

Seguir el bien por la desierta vía ${ }^{21}$.

Las copas de los árboles menea ${ }^{22}$;

Y en esta soledad el alma mía goza, sin envidiar cosa ninguna ${ }^{23}$,

Un apartado albergue le convida ${ }^{24}$

Cual si no hubiesen en el mundo sido! ${ }^{25}$

Al leer estos versos, es inevitable el recuerdo de la «Oda a la vida retirada».

18 Ibid., p. 41.

19 Ibid., p. 55.

20 Guillermo Díaz Plaja, España en su literatura, Barcelona, 1969, pp. 135-136.

21 Poesías, p. 38.

22 Ibíd., p. 39.

23 lbíd, p. 40.

24 Ibíd., p. 41.

25 Ibíd., p. 42. 
En el primer soneto queda también aludido el clásico lugar común del menosprecio de Corte. La originalidad del poeta es escasa. Recurre a la visión antropomórfica de la naturaleza, a la que confunde con una doncella y llama «amada mía». Su descripción física está sujeta a una evidente correspondencia asociativa:

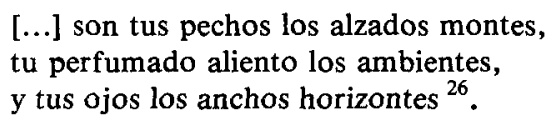

El tercero de los sonetos de este ciclo muestra de nuevo fuerte influencia de la corriente clásica de la poesía castellana. Es uno de los mejores suyos. Esta vez no es tanto Fray Luis - por efecto de un leve manierismo - como Garcilaso o. Herrera. El paisaje arcádico de Garcilaso se transforma en el soneto de Ros en naturaleza viva, sin ornamento ni idealización. El ruiseñor que canta en la noche, debajo de las ramas del laurel, no canta en un paraje solitario, ideal, donde la presencia humana resulta casi un milagro, sino que está aquí, «junto a la ventana» bien real del poeta. Así canta el ruiseñor de Olano:

\section{Celoso, ufano, amante, requerido, dice su amor con lánguido quejido y dulce y elevada consonancia ${ }^{27}$.}

«Celoso, ufano, amante, requerido...» Esta bella escala adjetiva, tan próxima a otras muy conocidas de nuestra Edad de Oro, como la de Herrera «Alegre, fértil, vario, fresco prado» ${ }^{28}$, o la de José de Sarabia,

26 Ibíd., p. 38.

27 Ibíd., p. 40.

28 El influjo herreriano es palmario en este soneto amoroso, no incorporado a Poesías, pero incluido en El doctor Lañuela, cit. en nota 6, pp. 151-152:

Yo desperté de un angustioso estado, creyendo que me hundia de repente; y á un beso que estalló sobre mi frente, alcé los ojos, y quedé asombrado.

No era mi Luz la que me habia besado; no habia dormido en sueño transparente; y al sacudirme el corazón ardiente mi Luz de luz buscaba enamorado.

Mas luego que corrí con rauda suma por el proyecto de mi vida entera, me dijo la experiencia: ;esa es Camila!...

Y era Camila como mansa bruma que en mi desordenada cabellera posó la boca y me besó tranquila. 
con la que da comienzo su Canción real a una mudanza («Ufano, alegre, altivo, enamorado») ${ }^{29}$, habla elocuentemente de la alianza estética que mantuvieron los poetas románticos con la clasicidad en el momento central del Romanticismo.

Los otros dos versos transcritos remiten a un estilo poético sereno y armonioso, de espiritualidad casi religiosa, tal y como se dio entre los poetas del Lake District ${ }^{30}$. Salvadas las naturales distancias, William Wordsworth, en el arranque de su poema «O nightingale!», inspirado en pasajes del «Upon appleton house to my Lord Fairfax» de Andrew Marvell, deja oír al ruiseñor con sublimidad parecida.

El soneto quinto y último de En la soledad, con el tema quevedesco de la consolatio mortis, evoca inevitablemente, como en otros poemas que más adelante veremos, a Jorge Manrique y la imagen del río que tiende a perderse en la mar. El verso de Ros es: «Río de la vida, corres á perderte»; con la variante de que ese mar en que ahora desemboca la vida es la Santa Providencia:

¿A dónde, pues, con bárbara violencia,
río de la vida, corres á perderte,
si no es tu mar la Santa Providencia?

El sentido de esta estrofa final del poema abre dos nuevas vías temáticas en estas Poesías: Dios y el destino humano.

Del tema de Dios se ocupan los sonetos «En la tribulación» ${ }^{32} \mathrm{y}$ «El hombre ante Dios $\gg{ }^{33}$. El primero plantea el problema del alma como esencia inmortal que ha de reintegrarse, tras la muerte, a la divinidad. El poeta se atreve a dudar de su inmortalidad, pero no de Dios: Dios era en la eternidad «Sér increado, Verbo de la vida». El afán de supervivencia ultraterrena le impulsa a dirigirse al Supremo Ser con sinceridad y vehemente y humilde ruego. No hay acento místico ni ascético; sólo un hombre torturado que quiere saber. Es un soneto "agonista", al modo de Unamuno (valga el anacronismo comparativo). Estos son sus tercetos, en los que se manifiesta la absoluta necesidad de respuesta:

29 Vid. Floresta de lírica española, I, edición y prólogo de José M. Blecua, Madrid, $1972^{3}$, pp. 289-292.

30 Cfr. B. Ifor Evans, Breve historia de la literatura inglesa, Buenos Aires, 1947, p. 50.

31 Poesias, p. 42.

32 Ibid., p. 43.

33 Ibíd., p. 44. 
Ahora dime, Señor (para que sienta fecundo mi pesar, y espere en calma á que se rompa la fatal concordia),

si este algo del no sér que me atormenta es mi esencia inmortal, ;el yo del alma! que ha de encontrar en $\mathrm{Ti}$ misericordia.

Otro soneto teñido de patetismo es el ya citado «El hombre ante Dios». Más que una oración, es un grito al imperturbable gesto divino. $\mathrm{El}$ poeta se reconoce culpable («en mi alma / Algo devorador hay que destroza / El bien...»), pero no por eso rehúye tomar conciencia de sí: «¡Así soy! ¡así soy!» Y pide a Dios ponga fin a su contradicción espiritual: «QQuiero morir, ó que me des la calma!», porque «Cuando lloro el corazón se goza / y cuando río el corazón suspira». Unamuno y Blas de Otero encuentran en estos versos de combate en la sombra con Dios un irrebatible precedente histórico.

Uno de los contados poemas que llevan fecha de composición es «En el nacimiento del Ebro» ${ }^{34}$. Se indica al pie: Reinosa, Mayo de 1837. Tenía entonces el poeta veintiocho años. El símbolo para representar el paso del hombre por la vida vuelve a ser el río, como en el quinto soneto de En la soledad. El río es en este caso concreto el Ebro, pero el poema pronto despega de la realidad inmediata y ese río se hace abstracto, universal; es todos y ninguno. La tópica analogía con el destino se desarrolla de este modo: las ondas «corren afanadas / Al mar, que es tumba y fin de su fortuna, / Cual lo es de mi ambición...». Pero algo singulariza a este poema, y es la conciencia de la propia frustración que abate al poeta:

iAy! que los dos lloramos adorando arpa, la gloria y la ambición frustradas,

Los «dos» son el río y él; la palabra «arpa», siguiendo la convención, sustituye a la poesía. Ros de Olano nos sorprende al confesar con simpática impudicia su incapacidad poética. Y esto en un momento aún temprano, de juventud. No es un pasaje aislado sin embargo. Con el mismo sentido, en La Gallomagia, pueden encontrarse estos elocuentes fragmentos:

Yo confieso que ya no valgo nada, y pues que soy la nulidad cantando, nada os importe relegar mi nombre ${ }^{35}$;

34 Ibid., p. 45. Dos poemas más llevan fecha de escritura: «A un soldado» (23 de abril de 1873) y «Meditaciones al pie del Cedro Deodara» (enero de 1880).

Ibíd., p. 142. 
Y líneas más abajo, otra autocondena:

$\mathrm{Y}$ hasta incorrecta, vaga y perezosa sale mi pretendida poesia; por pintar una, me salió otra $\operatorname{cosa}^{36}$,

¿Se deberán tomar literalmente estas «expansiones» o bien, por tratarse de un poema burlesco, han de verse como una desorbitada caricatura? La osadía de Ros de Olano, respóndase como se responda a la pregunta, confirma su merecida fama de escritor extravagante.

La fórmula comparativa de "En el nacimiento del Ebro» tiene continuación en el soneto dedicado al río Tajo: «Progresión» se titula ${ }^{37}$. Menos sinuoso y de contenido más profundo que aquél, «Progresión" gana en fluidez, en sencillez y en originalidad. Es un soneto ya de madurez literaria. Aparecía sin título en «Sinfonía», el capítulo de introducción a El doctor Lañuela, precedido del siguiente comentario del poeta: «La gravedad de las ideas se condensa; el libro es cauce por donde corre el espíritu y nosotros precipitamos su raudal: porque vamos tambien lanzados con ímpetu en la creciente de la vida desde el bautismo al epitafio; esto es, desde el nombre del individuo cristiano a la última fórmula del individuo humano» ${ }^{38}$.

Las resonancias clásicas (Manrique, Garcilaso, Fray Luis, en menor medida Herrera) cargadas de un vago romanticismo, van disipándose. El resultado es un soneto bien construido, cuyo esquema descansa en un doble símil - manantial: alma, río: idea- condensado en los versos finales:

Y así del alma, en cálidos rieles, la idea brota, y rauda se despeña, río caudal del pensamiento humano.

«Fatalidad» ${ }^{39} \mathrm{y}$ «Amor tardío ${ }^{40}$ tratan el tema amoroso. Si bien publicados el mismo año, 1873 , por la Revista de España ${ }^{41}$, parecen sonetos muy lejanos entre sí en cuanto a concepción y desarrollo.

\footnotetext{
36 Ibíd., p. 142. En ésta y en la anterior cita, obviamente el subrayado es nuestro.

37. Ibid., p. 53.

38 Op. cit., pp. 23-24.

39 Poesias, p. 49.

40 Ibid., p. 54.

41 «Sonetos», Revista de España, XXXIV (28 octubre, 1873), pp. 547 y 549. «Fatalidad» se titulaba allí "Círculos» y pasó a Poesías con grandes cambios; «Amor tardío» se llama "Convicto y confeso» en la versión de Revista.
} 
«Fatalidad» presenta un comienzo de delicadeza suma. Los dos primeros versos podrían pertenecer a un poema becqueriano:

De luz vestida en azul sereno, limpio reflejo de la casta luna...

(«Discreta y casta luna», dice Bécquer en una de sus rimas.) Pero luego las exclamaciones extemporáneas del poema rompen con el suave acento del comienzo y estropean la composición, que queda reducida a un cúmulo de tópicos románticos: la fatalidad, la mísera fortuna, el féretro, la pavorosa beldad, la muerte...

Si «Fatalidad» peca en exceso de frenesí («...El corazón sin freno / Triunfó del Hado...»), «Amor tardío» por lo contrario: es un soneto apagado, de rima pobre, y de una emoción inconvincente que no llega al lector. Y lo que es peor: no tiene ningún verso salvable. La incoherencia - uno de los defectos de fondo de Ros de Olano (el otro es su falta de pericia constructiva) - llega a su extremo al acometer el último terceto:

\footnotetext{
¡Musa de mi dolor!..., tuyo es mi canto, y al repetirlo el alma enamorada, sólo el suspiro que te mando es mío.
}

Al repasar estos sonetos de Ros, que conviene recordar fueron escritos a lo largo de toda su vida literaria, se advierten claramente diferenciadas tres direcciones o tendencias estéticas. Mas antes de describirlas hagamos una rápida puntualización. Pese a existir en la poesía de Ros esa marcada variedad, no puede hablarse propiamente de etapas, pues no hay una sucesiva transformación en el tiempo. Las tres tendencias conviven entre sí, igual que ocurre con los estilos diversos de su prosa: diversos, pero simultáneos ${ }^{42}$. No obstante, aunque no sea practicable el corte en segmontos cronológicos, hay en cada momento una tendencia que domina sobre las otras, y eso produce la ilusión -que aceptaremos por razones expositivas, aun cuando no sea absolutamente exacta- de que existe una cierta evolución en la poesía de Ros de Olano.

La primera tendencia es la clásico-romántica. Es decir, la más pura dentro del romanticismo. Como defendía Marcel Proust, «sólo los románticos saben leer las obras clásicas, porque las leen como han sido escritas, románticamente ${ }^{43}$. Dentro de esta tendencia, los poemas más logrados son aquellos en los que predomina, sobre la turbulencia de la

42 Cfr. E. Cassany, op. cit., p. 12.

43 M. Proust, Pastiches et mélanges, Paris, 1919, p. 267. 
inspiración, la mesura clásica. El equilibrio entre ambos componentes rara vez Ros lo consigue. Buen ejemplo de esta «etapa» de iniciación sería el tercer soneto de En la soledad, del que ya hemos hablado.

Más personal, desprendida del lastre de las influencias directas, es la tendencia que domina en el momento siguiente. La integran composiciones de mayor sencillez formal, de donde han desaparecido arcaísmos y neologismos gratuitos, al tiempo que adquieren una profundidad grave y trascendente. «Progresión», «El hombre ante Dios» y «En la tribulación», sonetos de los que ya nos hemos ocupado, corresponderían a esta línea de estilo. Pero quizá el más pleno dentro de la misma sea «No hay bien ni mal que cien años dure»" ${ }^{44}$ Se habla en él del doloroso paso del tiempo con sentimiento no lejano al de los sonetos morales y metafísicos de Quevedo:

El corazón es péndulo que advierte, golpe tras golpe, en una misma herida, ¡cuán próxima á la muerte anda la vida! ¡cuán cerca de la vida está la muerte!

En la siguiente estrofa, vida y muerte, entretejidas en la misma corriente, son empujadas por «el dolor hasta la inerte / Tumba», en donde a todos aguarda la «serena sombra». Los tercetos concluyen exponiendo la realidad íntima del ser: la conciencia del vivir como respuesta ante el propio sufrimiento:

Mas el dolor no mata en un instante, como la fiera daga; y la asemeja porque se clava con seguro tino:

y así en el seno, el péndulo oscilante, golpe tras golpe advierte al que se queja que va la vida andando su camino.

Por asociación con el reloj, siempre señalando el tiempo que pasa, al corazón humano se le llama «péndulo oscilante». Es símil reiterado; ya en el soneto V de En la soledad leíamos: «Y el corazón es péndulo [...] / con vaivén de dolor...» ${ }^{45}$.

En la evolución (aparente) de Olano se da, por último, una tercera guía o manifestación desconcertante. La llamaremos naturalismo grotesco. Los poemas encuadrables en tal estilo están desprovistos por lo

44 Poesías, p. 52. El capítulo XIII de El doctor Lañuela, titulado paradójicamente "Va sin epigrafe», se encabezaba con este soneto. El dicho popular de "No hay bien ni mal que cien años dure» con que se le titula en Poesías no figuraba en $L a$ nuela.

45 Ibíd., p. 42. 
general de emoción, sensorialidad e ideas -ingredientes pilares de la poesía-. Su interés, si caso, reside en su extravagancia.

El soneto, por ser un tipo de composición habitualmente aplicado a temas serios - y no olvidamos las increíbles distorsiones burlescas de Góngora, Quevedo, Lope y pocos más-, Ros de Olano apenas lo ha utilizado para sus estrafalarios usos. Como muestra suficiente de esta tendencia, basten los primeros versos, de gran hinchazón y desvaídos hipérbatos, de «Regalando una botella de vino añejo» ${ }^{46}$ :

De ésta que envío, anciana generosa, frágil tapada, indúbita doncella, cuanto de más edad, mucho más bella, rival temible á la mujer hermosa,

no queda en el origen ni aun la hojosa vid de que fué racimo y es botella...

La torpe rima, el énfasis de la versificación y lo inapropiado de ciertos vocablos (indúbita, añosa...) hacen de este soneto, aun tomándolo como broma alcohólica, un producto de dudosa calidad.

Una última composición comentaremos: «Eva» ${ }^{47}$. Es un soneto con algunas deficiencias. La adjetivación o es trivial («limpio espejo», (agua transparente», «ideal belleza»...) o resulta inadecuada, como es el caso de «rostro peregrino», por exigencia de rimar con "camino». No es ciertamente un buen poema. Pero contiene una idea sobre el arte que merece la pena considerar. Está expresada en el primer cuarteto. Se dice allí que «el Arte vislumbraba su destino / En la forma inicial de la serpiente». Luego la idea se despliega y visualiza mediante un ejemplo. Si sólo conociéramos del poeta sus sonetos, nos habría sorprendido una concepción semejante - hoy diríamos maudite-, pues distan mucho del diabólico arte. Eso al menos es lícito deducir partiendo de su experiencia como sonetista. No es así. Las siguientes series - La Pajarera, Doloridas y, sobre todo, Por pelar la pava y La Gallomagia- presentan un cambio de orientación -recuérdese: no en el tiempo-hacia un mundo donde lo esencial es lo amargo. Su poesía, como veremos, se vuelve ácida, descarnada, poco amable, y la burla y la seca mordacidad

46 Ibíd., p. 48.

47 Ibid., p. 50. 
hacen su aparición como recursos sustanciales asimilados al estilo. La poesía, entonces, sí, puede verse tentada por la serpiente ${ }^{48}$.

Pero veámoslo con más detenimiento.

\section{La Pajarera}

La Pajarera agrupa diecisiete poemas compuestos también en muy diversos momentos de la vida de Ros. Un cierto gusto por lo popular -y no sólo en cuanto al metro empleado- los interrelaciona y les procura unidad.

«Sueño» ${ }^{49}$, el primer poema de esta colección, representa un extraño y misterioso diálogo. El Poeta y La Visión son los personajes que dialogan. De corte reposadamente clásico, lo que lo enclava en la primera madurez del autor, su nueva espiritualidad, diríase casi mística, parece encarnar el ideal mallarmiano de la sugerencia: «Sugerir, he ahí el sueño». Tal vez sea el poema de Olano que retiene mayor cantidad de poesía, si es que la poesía fuese magnitud medible, y pudiera hablarse así.

El sentimiento místico a que hemos aludido se aprecia sobre todo en los siguientes versos, que compendian, con su innegable tono sanjuaniano, la simbología de la sublimidad:

Como el halcón tras de la garza huída, por los espacios seguiré tu vuelo;

alas de amor impulsan mi subida;

La intención del poema no está en principio clara. Su tema se repliega, se nos oculta. Pero, en su oscuridad, nos atreveríamos a sostener que Ros de Olano ha pretendido descifrar el sentido del acto creador. La conclusión a la que llega - sólo sugerida - es de estirpe simbolista. No de otro modo podía ser habiendo permanecido fiel a los postulados de escuela. Con singular perspicacia, Menéndez Pelayo señaló tempranamente a Ros de Olano como «precursor notorio de los enigmáticos escritores que ahora [1893] arman tanto ruido en Francia con nombre de decadentistas y simbolistas» ${ }^{50}$. El poema de Ros termina:

48 Lo mismo ocurre del lado de la prosa: sintomáticamente, la obra El doctor Lañuela es autodefinida como "fruta mordida por la serpiente de la experiencia». $O p$. cit., p. 25.

Poesías, pp. 59-60.

50

M. Menéndez Pelayo, op. cit., p. 395. 
(Habla la Visión al Poeta)

Cuando me alcance tu ambición inquieta, ¡acuérdate!, se quebrará en tus manos la lira del poeta.

Como Mallarmé había teorizado, «nombrar es suprimir las tres cuartas partes del goce del poema». El diálogo de Ros, efectivamente, aborda el drama de la belleza al querer apresarla. Poseer es perder.

La influencia de Espronceda se hace presente en ciertos poemas de La Pajarera. Es una influencia ocasional, que se da sólo en los primeros momentos de formación de Ros, pues éste, como señala Valera, «aunque grande amigo y admirador de Espronceda, [fue] muy distinto de él, como de su carácter independiente podía y debía esperarse» ${ }^{51}$.

Esta influencia romántica queda en algunos poemas diluida en medio del aporte no romántico (Manrique principalmente); pero, en otros, el peso del ascendente esproncediano no pasa desapercibido. Esto ocurre en el poema «En la orilla del mar» ${ }^{52}$, donde la desesperada actitud del cantor de Teresa es imitada sin encontrar un ajustado timbre de sinceridad:

La noche envuelve el mundo... Siento frío... ¡inmensa soledad!, tuya es la pena universal que llora en el rocío... Tuya será también la paz serena que de la muerte aguarda el pecho mío.

Reaparece otra vez Jorge Manrique en el poema «Cuesta abajo» ${ }^{53}$, escrito en octava real, el mismo esquema métrico de «Seamos justos» ${ }^{54}$. El tema del tiempo, el tiempo-río precipitándose en el manriqueño mar, es recreado discretamente en «Cuesta abajo» al introducir el motivo del engaño. Las aguas del vivir discurren atraídas engañosamente por los reclamos del mundo:

El árbol á la fuente protegía, dando apacible sombra a su venero;

pero la fuente de la sombra huía á la voz del arroyo lisonjero.

J. Valera, op. cit., p. 395.

52 Poesias, pp. 63-64.

53 Ibid., p. 68.

54 Ibíd., p. 82. «Seamos justos» aparece sin título en Lañuela, p. 173, tras este comentario, réplica a Confucio: «Dicen que dice Confucio, que la mujer es el sér más corruptor y más corruptible de todos los séres; pero si tal dijere, le faltó añadir que lo es sin culpa propia.» Sólo si se conoce este contexto, el título del poema, y aun el poema mismo, alcanzan a tener sentido completo. 
El arroyo, que alegre discurría, vióla llegar y la besó el primero; de allí fué al lecho de agitado río, y éste la sepultó en el mar bravío.

Menos frecuente que la octava, pero muy revalorizadora a partir del prerromanticismo, fue la copla manriqueña o de pie quebrado. Martínez de la Rosa, Espronceda, Zorrilla y la Avellaneda, entre otros poetas, volvieron a usarla ${ }^{5}$. También Ros de Olano. En «Contradicciones ${ }^{56}$, a base de tres sextillas simples de pie quebrado, la proximidad a Manrique se desliza peligrosamente hacia el plagio:

¿Dónde está el bien de la vida,

si la esperanza cumplida

da dolor?

Los demás poemas tienden a cristalizar en moldes populares: seguidillas, quintillas, romances... La seguidilla en sus dos modalidades - simple y compuesta - es el tipo de estrofa empleada con mayor abundancia. Siete composiciones la adoptan, total o parcialmente.

De corte igualmente popular, pero no de tradición hispánica en cuanto a la imaginería, sino árabe, son dos poemas de esta colección que llevan por título precisamente el nombre del modelo: «Kásida» ${ }^{57}$ y "Ménnhana» ${ }^{58}$. Estos poemas, acaso también "La ambición» ${ }^{59}$, agrupado con ellos, junto con el soneto «Simoún" ${ }^{60}$, constituyen lo que podríamos llamar los poemas del desierto. Debieron de ser escritos a partir de 1860, tras la intervención de Ros en la guerra de Africa (18591860).

La «Ménnhana» es una canción popular árabe, como en nota al pie el mismo poeta precisa, y en la que ha conjugado el tema erótico y el exótico sin demasiada fortuna. Iba incluida en Leyendas de África (1860) precedida de la siguiente frase: «Oíd una canción popular [de Tetuán] tomada al pié de la letra y vertida con el sabor que me ha sido posible» ${ }^{61}$. Al concluir la canción, agrega el autor este otro comentario:

55 Véase T. Navarro Tomás, Métrica española, New York, $1966^{2}$, pp. 301 y 348.

Poesias, p. 69.

57 Ibid., p. 65.

58 Ibid., pp. 85-86.

59 Ibid., p. 67.

60 Ibid., p. 47.

61 Citamos por Episodios militares, que incorporan, a modo de capítulo, el opúsculo Leyendas de Africa. A. Ros de Olano, Episodios..., Madrid, 1884, p. 168. 
"¿Quién no halla en estas estrofas la culta galantería de los árabes andaluces, mezclada con la cita de los medios que ofrece la localidad en que hoy habitan? ${ }^{62}$. La verdad es que aunque Tetuán tuviera «la cultura del árabe granadino con toda la fuerza moral del Hadj que llega de la Meca» ${ }^{63}$, según párrafos antes sostenía Ros de Olano, esta libre traslación es un débil remedo, una pieza orientalista desvaída como tantas otras edificadas por la fantasía romántica. Allí están los eternos «tesoros», «camellos», «perfumes», «collares» y «sultanes» de toda composición pretendidamente oriental. No faltan las alusiones ni a Alá ni a Bagdad. El desequilibrio se ha producido entre la envoltura métrica, muy rígida, y la naturalidad y frescura del mundo que evoca. Frente a sus exóticas maravillas, el verso, duro, medido, inflexible, no se desprende de la lógica ni de la tenacidad de la rima. Arabia ha sido occidentalizada:

\section{$\mathrm{Y}$ besaré tus pechos de azucenas, que en medio tienen un botón de rosa que se destaca apenas.}

«La hija del veterano» ${ }^{64}$ es uno de los dos romances incorporados a La Pajarera. No puede hablarse, en rigor, de poesía en este caso. Constituye una de esas composiciones a las que Jean Cohen designa con el nombre de "prosa versificada» ${ }^{65}$. Guarda correspondencia bastante directa con las Doloras de Campoamor.

Algo más colorista, pues introduce el tema de los gitanos, pero casi con la misma carencia de sentido poético, es «Las playeras» ${ }^{66}$, el otro romance, en el que no nos detendremos. Baste señalar que de los cinco o seis poemas de Ros sobre este tema, «Las playeras» es el único que no está compuesto en seguidillas, la forma estrófica que él mejor supo manejar. Cuando la empleó para dibujar escenas o ritos de los gitanos, logró indudablemente sus creaciones más plásticas. La siguiente estampa, a base de una seguidilla compuesta, prueba bien lo que decimos:

Figura tomada del natural

A la sombra de un chopo

yace un gitano,

tendido boca arriba,

62 Ibid., p. 170.

63 Ibild., p. 168.

64 Poesías, p. 70.

65 J. Cohen, Estructura del lenguaje poético, Madrid, 1970, p. 12.

66 Poesías, p. 72. 
muerto o borracho;

y por la boca,

la nariz y los ojos

le andan las moscas ${ }^{67}$.

Es un poema realista; de un realismo dotado de tremenda fuerza, que refleja la exacta brutalidad de la escena. Un gitano yace tendido. No se sabe si está durmiendo la borrachera o si acaso está muerto. Nadie se aproxima a él para ver qué le ocurre. Sólo las moscas revolotean por su cara. Lo que podría parecer, a primera vista, un cuadro indiferente, produce inquietud. Hasta el punto de crear en nosotros malestar, del mismo modo que los ligeros e impresionantes trazos de Los Caprichos de Goya. Pero la escena, gracias a su poder de sugestión, invita a ahondar bajo su superficie. La realidad del gitano tendido - «muerto o borracho»- traslada a otra realidad más amplia y universal, pero igualmente comprendida en la realidad. La postración de un ser marginado, la inhibición del hombre ante el problema ajeno, o la insolidaridad frente al sufrimiento, son significaciones posibles que se desprenden de la lectura del poema.

Campoamor, por quien Ros de Olano profesó ilimitada admiración, está en la base de este prosaísmo realista y sentimental. Pero la aspiración a la originalidad que Ros siempre mantuvo no sólo le sirve para amortiguar este influjo, sino para transformarlo en algo nuevo y propio: el lirismo cruel, al que desembocan sus más tardías composiciones, como este fragmento que damos de «Melancolías», y que puede entenderse - aparte su escaso valor actual - como el resultado de un proceso de exploración:

A un pajarillo oprimía un niño en su amor tirano, y al verlo ahogado decía:

¡Desdichada totovía, que se me ha muerto en la mano! ${ }^{68}$.

El cáustico contraste de esta quintilla se nos aparece, a la luz de la ulterior historia literaria, como antecedente claro de ciertas piezas poéticas de Valle-Inclán (La pipa de Kif agrupa varias de similar intención) y también, cómo no, de sus esperpentos. Este quizá sea el máximo va-

67 Ibíd., p. 81.

68 Ibíd., p. 73. 
lor, digno de destacarse y reconocerse, de toda la obra del general Ros de Olano ${ }^{69}$.

\section{Doloridas}

El título de esta sección indica bien a las claras qué modelo la inspira. Los dos primeros poemas que Ros adelantó de ella en revista, «Sobre el banco» y «Angelitos al cielo», todavía fueron sobrebautizados con un título que remitía más transparentemente a su origen: el de Dolora. Al frente de los poemas, una estrambótica carta-prólogo dirigida a Fernando León y Castillo, responsable de la revista que los acogía, explica el porqué de la elección de este título, aunque de modo poco verosímil: «Esto, mejor que yo lo indico, lo precisa mi amigo Campoamor en sus célebres Doloras [...] fijé mi exámen en el epígrafe Dolora. / Tal dicción no es una simple sinécdoque: en si encierra un emblema: el emblema significa contraccion del dolor ${ }^{70}$. El escrito continúa con un incondicional reconocimiento a Campoamor, del que entresacamos algunos enfervorizados elogios: «Resulta, pues, que quien entre nosotros ha dado en la flor de la pasionaria poética, es Ramón de Campoamor. [...] Sentimos todos; él siente por todos: como él ninguno. [...] Campoamor siente en humanidad conjunta: los más expresamos por modos y convenciones: él expresa en absoluto libre. / Su concepto del arte es la intuición. [...] Por cima de las reglas preceptuadas practica el arte por la belleza sentida. [...] Artista por naturaleza, es variado, sencillo y siempre original ${ }^{71}$. Tal vez en el dictado de esta admiración haya que buscar, como se desprende del final de su citada cartaprológo, la verdadera causa del título de Doloras que hace suyo Ros: «Prendado yo de esa su apesarada hermosura - escribe-, me puse á expresar doloras, sintiéndolas en andaluz, sin ser nativo de tan galana tierra, y sólo por ocasional contagio del trato con sus diversas gentes. Envio [...] las primeras muestras de doloras provinciales en que de Campoamor solo plágio el lema. En cuanto á lo demás, en vano intentaría aproximarme á la bellísima forma del maestro, y, felizmente, á su rigor escéptico no llego" ${ }^{72}$.

69 El juicio que emite Joaquín Marco sobre Ros es tajante: «Sus poesías tienden al guiñol y a lo desorbitado, precedente de Valle-Inclán.» Antologia..., cit. en nota 8, p. 92.

70 Revista de España, LIX (28 diciembre, 1877), p. 505.

71 Ibid., p. 506.

72 Ibid., pp. 506-507. 
El conjunto de poemas que integran estas «doloras» o Doloridas (once en total) es de calidad ínfima. Gran parte de los temas que ahí se abordan sublevan al lector de hoy. Es suficiente con leer los títulos para comprender la naturaleza lacrimógena de estas composiciones: «Sin el hijo», «La viuda del patriota de $1808 »$, «La abuela viuda y la nieta huérfana», «El llanto de la nieta», «En la necrópolis»...

Además de estos poemas desconsolados, Ros vuelve a hablarnos del paso del tiempo («Los dos sueños»), de la gitanería («Angelitos al cielo»), y en una décima — que desde luego no es ejemplo de décima-, de su concepción del arte («En el Museo del Louvre»). Con todo, son éstos de los pocos poemas en que merece detenerse.

En «Los dos sueños» ${ }^{73}$ el transcurso de la vida está simbolizado por la pérdida de la niñez. Una muchacha, al despertar, recuerda que el sueño de esa noche es el mismo (y distinto a la vez, inexplicablemente) que el que tuvo el día de su primera comunión. Con tan simple e ingenuo juego de superposición onírica se concreta el paso de la infancia a la adolescencia.

«Angelitos al cielo» ${ }^{74}$ es de los poemas menos endebles de esta sección. Melodramática es la escena del entierro del niño gitano. Pero tiene fuerza. En algún verso se quiebra la cadencia, con lo que se consigue un efecto de desgarramiento muy oportuno. Le hubiera beneficiado suprimir dos o tres seguidillas de las doce de que se compone ( $\mathrm{y}$ eso que una ya lo fue al pasar a su estado final).

En el poema «En el Museo del Louvre» ${ }^{75}$, la Venus de Milo es tomada como encarnación de la estética que proclama «el arte por la belleza». Ante la estatua, piensa entristecido el poeta que el arte "hoy nos da otra religión», por la que el artista es capaz de sacrificar sus emociones (sus «lágrimas») con tal de obtener el «beso» puro de la belleza. $\mathrm{He}$ aquí los últimos versos de este poema antiparnasianista:

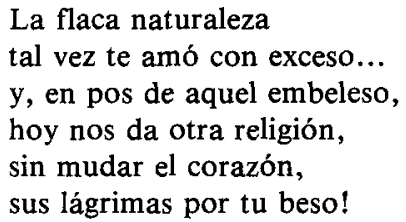

La flaca naturaleza

tal vez te amó con exceso...

$y$, en pos de aquel embeleso,

hoy nos da otra religión,

sin mudar el corazón,

sus lágrimas por tu beso!

73 Poesías, p. 89. Escrito originariamente en dodecasílabos agudos (diecisiete en total), el poema fue desdoblado en unidades hexasílabas (treinta y cuatro versos); apareció, pues, en sú versión definitiva de Poesías como romancillo agudo.

74 Ibíd., p. 95.

75 Ibíd., p. 108. 
Tema nuevo en la poesía de Olano, pero muy tratado durante el romanticismo, es el del ajusticiado ${ }^{76}$. «Sobre el banco ${ }^{77}$ y «El Penado ${ }^{78}$ manejan este asunto. El primero de ellos, en seguidillas compuestas, mantiene el tono irónico y amargo de las más aceptables composiciones de Olano; el segundo está constituido por tres quintillas acompañadas de estribillo, y «parece una de esas coplas - son palabras de Marina Mayoral- surgidas al hilo de los hechos, que conservan todavía el calor y el desgarro de lo reciente» ${ }^{79}$. En ambos, el infortunado amor con una «hembra ingrata» es la causa de la condena.

La filosofía antipoética de Campoamor reaparece en varios momentos con desigual fortuna. Como las Doloras (1846), algunas piezas de Dolidas insertan diálogo entre los personajes, que abrumadoramente, como hemos visto, son seres desvalidos, marginados. Razón sobrada tuvo don Juan Valera al predecir en 1856, o sea, veinte años antes de que a Ros de Olano se le ocurriera secundar a Campoamor en sus Doloras, que eran éstas un espécimen poético de difícil porvenir. «Sólo diré - argüía Valera ${ }^{80}$ - que temo mucho que nadie, sino el señor Campoamor, haga nunca Doloras, y que si alguno las hiciere, y procurare imitarle, las hará pésimas.»

De las once composiciones agrupadas en esta sección, diez son propiamente dolidas (sentimentalismo, concisión, arte menor); la undécima, colocada en el último lugar, es una larga elegía - compuesta en silvas - que nada tiene que ver con el resto. «Meditaciones al pie del Cedro Deodara de la plaza de las Cortes» es su título completo. Escrita en enero de 1880 , seis años antes de la muerte de su autor, fue publicada en 1881 por la Revista de España ${ }^{81}$. De once silvas consta. Llega a sumar los ciento treinta y dos versos.

El realismo de «Meditaciones» ${ }^{82}$, como el de toda la poesía realista de Olano, va unido, como era esperable, a un tono elevado y recitativo

\footnotetext{
76 Véase E. Allison Peers, Historia del movimiento romántico español, II, Madrid, $1973^{2}$, pp. 360-361.

77 Poesías, p. 99. El poema, que constaba de once estrofas en su versión de Revista de España, LIX (28 diciembre, 1877), pp. 507-509, se reduce en Poesías a tan sólo seis.

78 Ibid., p. 104.

79 M. Mayoral, Análisis de textos, Madrid, $1977^{2}$, p. 62.

80 J. Valera, «Obras poéticas de Campoamor», en Obras completas, Madrid, 1942, II, p. 58.

81 Revista de España, LXXX (13 mayo, 1881), pp. 57-63. Pasó a Poesías muy reelaborada, con supresiones y añadidos importantes.

Poesías, pp. 109-114.
} 
muy de época (Núñez de Arce, Bartrina, Campoamor), que nunca aspira a decir las cosas con sencillez. Abunda en el poema la exclamación retórica y el hipérbaton ocioso, manejado sin tino («para aguardar la sopa / Del fraile desperdicios»; «los que fueron / Pobladores del Líbano gigantes»), así como el pronombre enclítico (sentéme, vióse, álzase, mudóse...) y el énfasis debido a la continua anteposición del calificativo $(81,2 \%$ de los casos).

Rasgos también frecuentes en «Meditaciones...» son el uso de neologismos (cimbria, rostrario, espirante...) y el uso arcaizante de la lengua, valiéndose de giros sintácticos latinos (ya mencionamos los hipérbatos), cuando no de verdaderos arcaísmos (empleo de so por bajo, de do por donde, de hora por ahora) o léxico inusual (cinérea, treno, gritería...). Para resaltar aún más este carácter anacrónico, Ros de Olano no duda en emplear la diéresis -ortográficamente - para la escanción de un verso: «Misterïosa y vaga melodía».

En cuanto a la adjetivación, el porcentaje de calificativos no pertinentes $(11,1 \%$, ninguno por sinestesia) habla de una observancia normativa casi estricta. Es un índice muy bajo. Menos de la mitad del alcanzado por otros escritores coetáneos, como Lamartine, Víctor Hugo o Alfred de Vigny ${ }^{83}$. Y hasta esas raras «impertinencias» adjetivas son debidas a una tendencia antropomórfica convencional: «riente césped», «dormida escarcha», «desnuda arena», «venerables edificios».

Se pone así de manifiesto, porcentualmente, algo que ya sabíamos: que el realismo de este género de poesía, bien que encauzado en verso, no se aparta demasiado del régimen de la prosa.

El asunto de «Meditaciones...» es la reconsideración histórica del pasado. El poeta, al pie del gigantesco cedro oriental, se siente de pronto trasladado - «¿En dónde estoy?», pregunta- a otras épocas. Gracias a esta violenta superposición temporal, presencia las transformaciones que fueron alterando aquel paisaje que se extiende a su alrededor: desde cuando éste era sólo pradera silvestre, poblada de animales e «ignorada de los hombres», hasta que se convierte en la villa de Madrid. El poema es rico en alusiones históricas: la conquista árabe, San Isidro, los años de hambre y miseria social, Felipe II (el «Tétrico Faraón [...], / Atizador de la inhumana hoguera»), la estatua de Cervantes... En medio del correr de los siglos, tan sólo el cedro, como símbolo de fidelidad, permanece sin mudanza en la tierra.

83 Véase, J. Cohen, op. cit., p. 119. 
Concluye el poema -el más ambicioso de Ros- con una emocionante invocación al viejo árbol:

\author{
Noble Cedro doliente, \\ cautivo en suelo hispano; \\ gárrulo adorno de jardín urbano \\ que no olvidas tu Reino del Oriente: \\ falto de amor y del nativo ambiente, \\ con unas ramas tiendes alto vuelo \\ de aspiración divina, \\ misericordia demandando al cielo, \\ y otras abates al humilde suelo, \\ á do la muerte pálida te inclina... \\ - pero no estarás solo, triste amigo, \\ en tal tribulación, mientras aliente \\ $\mathrm{mi}$ ancianidad, de tu dolor testigo...- \\ ¿Todos los días que de vida cuente \\ vendré a la tarde á conversar contigo!
}

En efecto; como explica Alarcón en su citado prólogo, el «Cedro Deodara se levantaba hace pocos días en la Plaza de las Cortes, y fue arrancado de cuajo por el espantoso huracán de 12 de mayo último» (Alarcón firma el prólogo el 19 de junio de 1886). Y continúa: «Muchísimas tardes, durante los años de su ancianidad, se ha visto al General Ros de Olano sentado bajo aquel arrogantísimo árbol extranjero, que le ha precedido en la muertes ${ }^{84}$.

La correspondencia progresiva entre anciano poeta y árbol, testigos desengañados del transcurrir de la historia, cabe entenderse también como símbolo primario de alianza entre el hombre y la tierra.

\title{
«Por pelar la pava» $\mathbf{y}$ «La Gallomagia»
}

Conviene describir juntas estas dos composiciones porque participan básicamente de las mismas características definidoras: realismo popular, rima ligera y superabundante, carácter burlesco. Mas este último se acentúa hasta tal punto que llega a ser, por sí solo, la sustancia principal del poema. Todo deviene puro pretexto para tejer el desconcertante juego. $\mathrm{El}$ objetivo parece centrarse -luego veremos que algo más oculto hay tras esa apariencia - en el deseo de sorprender con el absurdo o el ridículo.

La rima, por ejemplo, es intencionalmente descabellada. Ros la 
emplea con el fin de provocar el desatino. Así, se atreve a rimar versos como los que a continuación se citan:

$$
\begin{aligned}
& \text { [...] mas hoy rechaza } \\
& \text { mi edad cansada fustigar caballos, } \\
& \text { y para cazador me sobran callos }{ }^{85} \text {. } \\
& \text { Vió entrar con el torero de Sevilla } \\
& \text { al emigrado que le dió papilla }{ }^{86} \text {. }
\end{aligned}
$$

Versos de la jocundidad de éstos se encuentran en escritores del XVIII, como Vicente García de la Huerta, José Iglesias de la Casa o Juan Pablo Forner; pero en ellos hay una intención satírica contra sus enemigos - lección aprendida de Quevedo- que, en cierto modo, justifica la facilidad hilarante de sus rimas.

Por pelar la pava: tradición infernal ${ }^{87}$ es un extenso y aburrido romance en nueve partes. Se basa en una leyenda popular, conocida en Sevilla (donde se sitúan los hechos) como «el milagro de la pava». Dos pretendientes rivales, cuenta la leyenda, se batieron por el amor de una misma mujer y se dieron muerte a los pies de una imagen de la Virgen. Como castigo divino, al recibir la Extremaunción, sus cuerpos saltaron despedazados. Goya se inspiró en esta leyenda, deja dicho Ros de Olano en la «Conclusión» de su romance, para pintar el cuadro Serenata:

Si es conseja ó sucedido, Dios lo sabe, y Dios me valga:

Goya lo tuvo por cierto, y pintó la Serenata ${ }^{88}$.

Ros de Olano relata la historia con gran distancia, llevando a pasajes de impresionante violencia, como el del estallido de los cadáveres, elementos de humor -raro humor-; una mezcla que produce en el lector verdadera perplejidad:

\footnotetext{
El cura creyólos vivos; el comadrón lo juraba.

Por si o por no, dijo el cura:

"Per istam unctionen sanctam...",

y al «amén» dieron un bote

aquellos cuerpos sin alma, con el ímpetu que suben, con el ímpetu que saltan, rebatidas contra el suelo
}

\footnotetext{
85 De La Gallomagia, Poesías, p. 141.

86 Ibid., p. 147.

87 Ibid., pp. 117-135.

88 Ibíd., p. 135.
} 
pelotas de goma elástica;

$y$, parejos por el aire,

estirados como ranas,

cayeron como dos troncos,

sonando como dos tablas ${ }^{89}$.

Lo estrafalario se persigue como un fin en sí mismo. La fundamental diferencia con el esperpento de Valle-Inclán radica ahí; mientras éste desorbita la realidad para hacer más patente su desquiciamiento (absurdas normas, desigualdades, injusticias, actitudes hipócritas...), Ros de Olano no pretende revelar nada. Apenas, en La Gallomagia, hay un amago de crítica nacional y patriótica, pero muy encubierta por la sangrienta anécdota (oscuramente alegórica) de la lucha de gallos. Eso es todo. Muy justo era Alarcón al declarar: «llamaré la atención sobre el cántico épico La Gallomagia, donde, á vuelta de felices recuerdos de La Gatomaquia y de La Mosquea, abundan rarezas y. reconditeces $"{ }^{90}$. Rarezas que no logran tener gracia; reconditeces que enturbian el lenguaje popular en lugar de revitalizarlo, como Ros pretendía. No sin razón reconoce él mismo en La Gallomagia que su «versi-prosa» es «incorrecta, vaga y perezosa»"

A la sombra de Villaviciosa y Lope, La Gallomagia ${ }^{92}$ continúa el género paródico de la épica culta. Consta de un solo canto, que lleva en nota esta jactanciosa aclaración: «El escritor no ha llegado a escribir otro» ${ }^{93}$. Las veintinueve octavas que componen este «Canto Primero» (y único) van precedidas de otra titulada «Argumento del primer canto». Es un espejo de toda la obra:

Donde hallará el lector menos sapiente que en cada octava asoma un desatino, como al que ensarta coplas de repente le saca el consonante de camino.

Mas si hay quien lea, pío o consecuente, mi canto un tanto cuanto calaíno, verá que en tan insípido monólogo burla burlando se establece un prólogo ${ }^{94}$.

Aun cuando, ciertamente, en cada octava asome un desatino, la parodia de Ros se recorta, fría, como una rígida caricatura del mundo.

\footnotetext{
89 Ibíd., pp. 133-134.

90 P. A. de Alarcón, op. cit., p. 30.

91 Poesias, p. 142.

92 Ibid., pp. 139-148.

93 Ibíd., p. 139.

94 Ibíd., p. 139.
} 
Su extralimitación no tiene objeto. Lo mejor sin duda del poema es el subtítulo: «Poema á espuela viva, escrito por Fulano Zurita, bachiller en patas de gallo, licenciado en puyas y doctor en ambos espolones». La tensión dinámica de la frase cobra ahí un vigor expresionista que la aproxima, como ha visto la crítica, al lenguaje distorsionado del esperpento ${ }^{95}$.

\section{«Lenguaje de las Estaciones»}

$\mathrm{Al}$ igual que «Meditaciones al pie del Cedro Deodara», Lenguaje de las Estaciones ${ }^{96}$ ofrece un estilo libre de influencias directas. No escapa el verso al prosaísmo realista impuesto por la reacción antirromántica, pero en ocasiones el poeta logra despegar hacia una poesía inspirada y estremecida, próxima al verdadero lirismo.

Sucede esto particularmente en aquellos pasajes en los que lo narrativo queda desplazado por lo descriptivo. La acción, entonces, se detiene en la equilibrada contemplación, y la naturaleza pasa a ocupar el primer plano, para ser cantada no como simple escenario, sino como un hecho portentoso en sí mismo. De ahí que los fragmentos dedicados a describir el amanecer o la tormenta sean lo más notable de este Lenguaje de las Estaciones.

$\mathrm{El}$ poema se distribuye conforme al esquema siguiente:

Dedicatoria (tres octavas reales)

En el invierno

I. «El monte» (romance; rima de formación: $o-o$ )

II. «El hogar» (romance; $e-o$ )

En la primavera
I. «La mañana» (romance; $a-a$ )
II. «La golondrina» (romance; $e-a$ )

En el verano

I. «De la casa al árbol, y del árbol a la casa» (romance; $u$-o)

II. «La tempestad» (romance; $e-e$ )

En el otoño
I. «En la tarde» (romance; $a-o$ )
II. «En la noche» (romance; $a-o$ )

Un fenómeno curioso de reabsorción clásica se produce. Los mitos

\footnotetext{
5 J. Servera Baño, Ramón del Valle-Inclán, Madrid, 1983, pp. 107-108.

Poesías, pp. 151-204.
} 
grecolatinos - y esto es algo más que un indicio- reaparecen en los octosílabos de Ros de Olano (Flora, Amaltea, Cupido...) como antes en la lírica de Meléndez. Si esta neoclasicidad no siempre logra mitigar el realismo, al menos proporciona al poema un margen de fantasía superior. Estos versos que recrean el mito del nacimiento de Venus son buena comprobación:

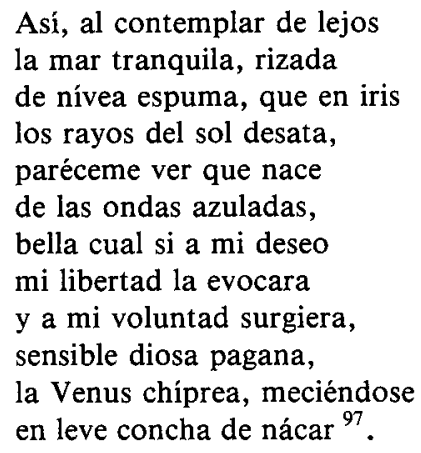

O estos otros sobre el advenimiento de la Aurora :

Ungida en blando rocío despierta amorosa el alba, tímida beldad que en sueños su amante, el Sol, busca y llama:

claros sus ojos azules de luminosas pestañas, al beber luz en los cielos, la luz al suelo derraman ${ }^{98}$.

Años después, el Rubén Darío de Epístolas y poemas (1885), Abrojos (1887), Otoñales (1887), arrancaría de este mismo punto de inflexión dieciochesco. De pre-modernista, por su estética desmaterializadora y cromática, podrían conceptuarse desde luego varios momentos de Lenguaje de las Estaciones. La descripción del mitológico nacimiento de Venus, al que antes nos referimos, no sólo es un preludio formal del movimiento instaurado por Rubén, sino que concluye con una visión órfica del Universo que no puede ser ya más del gusto modernista. He aquí cómo Venus es llevada por el mar hasta la orilla:

Las sueltas madejas áureas, con pompa de blancos cisnes que sumisos acompañan,

Ibid., p. 169. 
y Céfiros y Nereidas

que la acercan á la playa.

Oigo el plácido concierto

de los orbes en la estancia

del Infinito, do viven,

giran, se atraen y se aman,

y esa sublime armonía

es el suspiro, es el habla

de la Creación entera

que suspira enamorada ${ }^{99}$.

Junto a esta tendencia se desarrolla otra de corte verista, que trata de hallar la emoción en los pequeños sucesos de la vida diaria y en los sentimientos del hombre puro y sencillo. A este verismo corresponden los fragmentos más prosaicos del poema. La sentimentalidad tradicionalista de Gabriel y Galán encuentra aquí su primer ascendente:

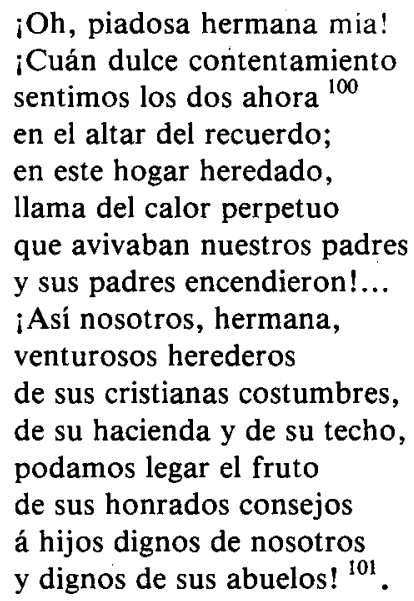

La doble corriente - neoclásica y doméstica - arraiga asimismo en otras literaturas europeas del momento. Es el caso de Italia, donde Giacomo Zanella, retomando el sentir académico de Aleardo Aleardi y de Giovanni Prati, prolonga la tradición clasicista, mientras que Vittorio Betteloni y Olindi Guerrini se dedican a cultivar una poesía verista, inspirada en el menudo acontecer de la vida, sin más pretensiones que llegar a hacerse entender por todos.

Ros de Olano, lo hemos visto, persigue conciliar en los últimos

Ibíd., p. 175.

100 Leemos «los» en lugar de «las», subsanando así lo que es una evidente errata del original.

101 Poesías, pp. 165-166. 
años de su actividad literaria ambas corrientes. Lenguaje de las Estaciones es el resultado de tal esfuerzo. Lo que consigue es un estilo dispar cuya monotonía se agrava por la rima (rima interna) excesiva, los períodos sintácticos inflexibles y la falta de sorpresa en la expresión. Cuando narra, lo hace sin seguir un hilo argumental, guiado por un instinto más novelero que metódico.

A pesar de los defectos señalados, a la obra de Ros de Olano es preciso reconocerle un valor histórico importante -aparte de aquellos aciertos que intrínsecamente hacen estimables aislados poemas- por cuanto contribuyó al nacimiento de un género nuevo, los esperpentos, y preparó la sensibilidad a otras encrucijadas estéticas decisivas (simbolismo, verismo, modernismo...).

«En sus Poesías - como resume el P. Blanco García ${ }^{102}$ - hay algo para todos los gustos: realismo descriptivo, desbordamientos románticos, miniaturas irrepochables de forma y asomo de amargura sarcástica y corrosiva.» El escrutinio que de la obra lírica de Ros hizo Menéndez Pelayo apenas variaría del verificado por el lector de hoy. De entre sus poemas volveríamos a entresacar «media docena de sonetos de primer orden, dignos de los honores de cualquier Antología castellana; los bellos romances descriptivos del Lenguaje de las Estaciones, a pesar de algunas tintas excesivamente grises, que de vez en cuando rompen la armonía bucólica y venatoria del conjunto; [...] algunas octavas del poema burlesco La Gallomagia, y aquí y allá, aun en composiciones más desiguales, trozos arrogantes de descripción poética, como [...] Meditación sobre el Cedro Deodara (sic) ${ }^{103}$.

Pero en estas palabras de Menéndez Pelayo ese mismo lector actual echa de menos una consideración -imposible por otra parte en el fin de siglo, pues es el efecto retroactivo de la historia el que la motiva-, acerca del papel de puente desempeñado por Ros. De un lado, el Arcipreste, la picaresca, cierto Cervantes, Quevedo; de otro, el despliegue expresionista que, forjado en la Europa central de comienzos del siglo XX, dentro de España cristaliza en la figura máxima de Valle-Inclán. Entre esas dos mesetas temporales, la obra de Ros de Olano supone una línea de unión y continuidad. ¿Cómo negarlo a la vista de los casos aducidos hasta ahora sobre su poesía? Fuera de ella, otros pasajes hay que lo corroboran con evidencia incontestable, como la es-

102 Francisco Blanco García, La litenatura española en el siglo XIX, I, Madrid, 1891, pp. 190-191. 
cenilla esperpéntica que figura al frente del capítulo XV de $E l$ doctor Lañuela, y que reproducimos tal cual allí aparece ${ }^{104}$ :

(La viuda y dos ganapanes cargados con un ataúd, que van camino del cementerio.)

Primer Ganapan.

Pesa mucho este difunto para viajar de limosna.

Segundo Ganapan.

Ya estoy por soltar la carga y que lo lleve la ronda.

La viuda (llorando).

Hermanos, por caridad, que está muy cerca la hoya.

Un centinela.

¿Quien vive?

La viuda (llorando)

¡Un muerto!...

El centinela.

Que pase

a que la tierra le coma.

El enterrador.

¿El cadáver trae permiso

del cura de la partoquia?

No llegó a decir explícitamente Ros de Olano, como lo pudo ValleInclán a su tiempo, que su arte aspiraba a la «superación del dolor y de la risa». Pero en las frases finales de su recién citada «novela», El doctor Lañuela, se vierte una idea similar ${ }^{105}$ :

...muchos lectores -escribe Ros - habrán cerrado las [páginas] del Doctor Lañuela preguntándose.

- ¿Esto es una novela? no.

- ¿Es acaso un poema? tampoco.

- ¿Pues qué clase de libro es éste tan sin género conocido?

Yo-lo diré:

Es historia del corazon donde el dolor adultera con la risa; y del consorcio nace un libro híbrido... iAy! ¡mil veces ay!...

Consorcio de dolor y risa, que, en los momentos de más temperatura de su trabajo, logra (igual que en Valle) la «deformación grotesca» - Por pelar la pava o La Gallomagia son obras hijas de esa

\footnotetext{
104 Op. cit., p. 223.

105 Ibid., p. 282.
} 
deformación-, pero sin someterla a la «matemática perfecta» con que aquél se impuso a los demonios de su genio creador. Valle-Inclán está siempre por encima de la pesadilla dislocada que él mismo ha puesto en pie; él la conduce a donde se propone y la carga de significados. La literatura de Ros, aunque roce la pesadilla, es obra más bien de «sonámbulo», como precisara Menéndez Pelayo ${ }^{106}$; no conduce, sino que es conducida. Se queda en mueca, en remedo de dolor.

El punto de partida es el de Valle: la palabra como escapatoria, invitación a huir desde el dolor a la risa — «Oh musa del dolor! contigo río», dice un verso de La Gallomagia ${ }^{107}$-; le faltó, en cambio, dotar a esa palabra de intención para conferir profundidad y verdad al drama humano. Con todo, enlazó la literatura con el arte tremendo de Goya, tratando de encontrar el punto donde lo popular y lo trágico consiguen su más exacta expresión.

106 Dice refiriéndose a Lañuela que parece «visión de sonámbulo, con chispazos de ingenio, en medio de un diluvio de arcaísmos, neologismos y retorceduras de frase». El juicio, exacto, es extensible a toda la obra de Ros, y particularmente a sus poemas. M. Menéndez Pelayo, Estudios y discursos de critica histórica y literaria, VII, Obras completas, XII, Santander, 1942, p. 281.

Poesias, p. 141. 